\title{
Study on Aviation Logistics Park Facilities Layout
}

\author{
Bao Jianmei \\ School of Economic and Management \\ Shengyang Aerospace University \\ Shengyang, China \\ Baojianmei@sau.edu.cn
}

\begin{abstract}
Since China's entry into WHO, high-tech and high value-added products have been increasing and the speed of industrial structure adjustment is accelerated, which not only puts forward the requirement on comprehensive logistics service toward air cargo transportation enterprises, but also raises the demand on air freight. In order to meet the demand on aviation logistics development, all large airports establish an aviation logistics park as an important measure to improve their airport freight competition and to improve their aviation logistics service. Blind construction will probably cause many problems such as too-large scales, improper functions and unreasonable layout, which would pose a problem for the future aviation logistics park operation.
\end{abstract}

Keywords-Logistics; Park; Layout;Airport

\section{INTRODUCTION}

From 1920s, USA used the logistics theory and put it into practice, which went through three stages, namely, physical distribution, integrated logistics and supply chain management. At present, much logistics theory research in foreign countries starts from supply-chain logistics management to make research on all logistics sections. UPs, DHL, FedEx and many other companies have become the leaders in the field due to the philosophy of integration. Logistics parks are the result of the modern logistics industry. They stand for a new logistics management mode. The first park is in Japan. Because it has many advantages, it was spread to Asian countries from many European countries in a short period.

1) The overall layout makes air economic development synchronize with land economic development in the park.

2) The overall layout makes functional areas perfect to accelerate construction of logistics parks.

3) The overall layout makes the industrial structure improved to try to make development of aviation logistics.

4) Increase of Innovation and R \& D.

Japan is the first that made development of logistics parks. In this way, the Tokyo logistics park greatly reduced traffic pressure. It was encouraged and obtained support from all sectors of society. It enjoyed favorable prices in purchase of land. Germany is different from Japan in this aspect. It has another popular mode. Germany has the mode of national construction, company management and enterprises' self operation. Rhonda Lyons. The traffic forecast by Rhonda Lyons through the Federal Aviation Administration shows that at present the national aviation system operates with the overload $(150 \%)$. Over the next 20 years, it will be at an alarming rate of $250 \%$, which requires us to optimize the aviation logistics systems for supply of safe and efficient aviation logistics service.

\section{OUTLINE OF LOGISTICS PARKS}

About aviation logistics parks, there is still no accurate and unified concept. According to the domestic construction of the aviation cargo hubs and according to the experiences of large logistics countries such as Japan and Germany, summarization to have some large logistics hubs is not just in order to realize the delivery of cargo. A lot of relevant contents (for example, informationalized management, transportation management and effect on the industry) is involved. All in all, we can make the conclusion on this,

A logistics park is a functional park with economic development nature to make relative concentrated construction and development on the joints of logistics organization management. Moreover, it is also an economic park with industrial development through many activities such as synchronization with related logistics, reduction of relevant expenditure, improvement of work efficiency, improvement of enterprise service contents, procurement of raw materials and convenience to make direct connection with the consumption areas.

\section{AVIATION LOGISTICS PARKS AND THEIR FUNCTIONAL FRAME}

Aviation logistics is very important in the modern society because aviation logistics is very safe and it is able to timely make delivery of goods to the destination. These characteristics all meet the needs of contemporary people. Due to the rapid development of Xi'an logistics, the former airport logistics cannot meet its requirements. To be more competitive, airlines must make transformation of their own business to reach informationalizaiton and meet requirement on modern development. Therefore, aviation logistics parks are established. .

Aviation logistics parks provide an effective platform for aviation logistics, and the industries with aviation logistics as core link with each other to form an effective industrial chain. In addition to providing aviation, a freight platform, a logistics information network platform, a management and service platform, an environmental policy platform, customs, inspection and other services, they can also use their the advantage to share the thirdparty logistics service. 


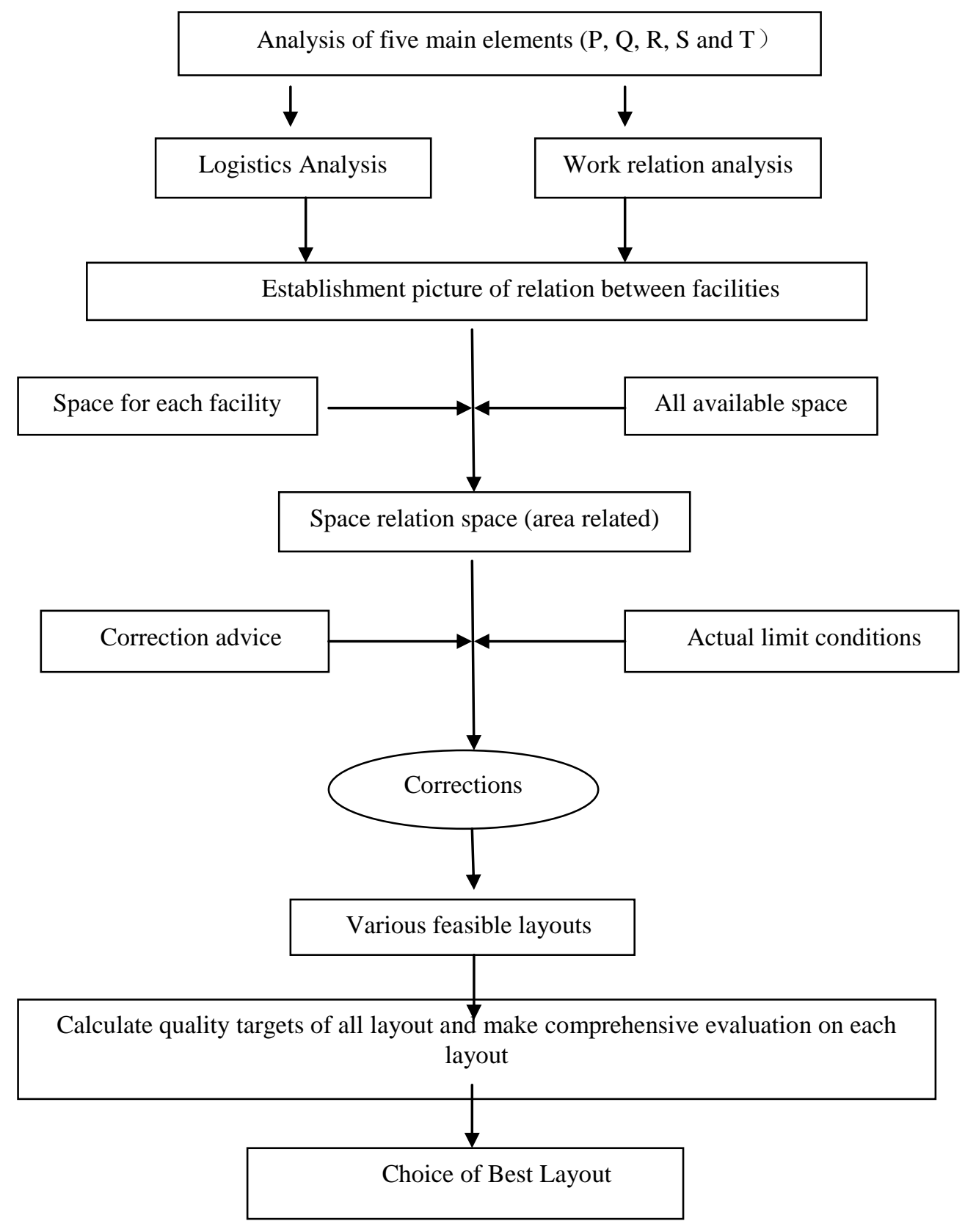

Figure 1. SLP Design Procedure Diagram

Therefore, the birth of aviation logistics parks is inevitable. According to their characteristics, we can know that the focus of aviation logistics parks can be summarized as follows,

1. Mainly displayed in focus by airlines and related enterprises,

2. The integration of the business is also recognized and welcomed by businessmen,

3. Aviation logistics parks also have many related services such as distribution, sampling, transportation, storage, loading and unloading, handling and logistics information processing.

4. The aviation logistics parks with export supervision and bonding functions have stronger attraction.

Due to development of the national economy, the demand on aviation logistics grows with each passing day.
What is more, aviation logistics has led to rapid development in many fields such as land transportation. Many logistics enterprises have increased a lot of related value-added services. Thus this improves their competitiveness and drive development of related businesses that the aviation logistics parks constantly develop on the right way.

\section{Method of AVIATION LOGISTICS PARK FACILITIES LAYOUT}

A. Guiding Thought and Principles in Aviation Logistics Park Layout

1) Guiding Thought for Aviation Logistics Park Layout 
Fast operation of goods transportation is the first of important items of modern logistics. This is also an important index of logistics parks' integrated transport function, especially for aviation logistics parks with aviation transport modes as main accordance. On this basis, the task of the construction for an aviation logistics park is to have better connection between suppliers and demanders in a close way and to realize good communication between the two parties. With aviation transportation and with aviation logistics parks as the distribution center of all goods, combination between aviation and other fast freight ways is made to reach a mutually cohesive whole. The examples are combination between aviation transportation and land transportation, combination between land transportation and aviation transportation and combination between ocean shipment, aviation transportation and land transportation. In layout of aviation logistics parks, we must at first specify this and reach fast, smooth and ordered delivery of goods through close combination of the three.

To achieve smoother and rapider transportation, we must at first specify that the ultimate purpose and ultimate result of the aviation logistics layout must sufficiently display the effective organization of the logistics for aviation logistics parks and display the largest functions of the parks. At present, the layout of logistics parks has the two following tendencies, namely, "entity" and "virtual". "Entity" tendency at first builds entities with a certain scale. Then, effective layout and extension of the entity should be made. The next task is gradual expansion of the business. Of course, this is closely related to quality service. Due to this, we should plan the organization to achieve highly effective transportation of all goods. The first is to set up a small business entity and then to do the next step in the layout. Medium scale and large-scale layout is realized. Integration of all tangible cargo warehousing (including logistics warehousing and cargo delivery) and transportation can make all cargo transportation visible. The "Virtual" tendency refers to taking function layout and implementation in the parks as important basis with the precondition of realizing all functions and to having the organizing and coordinating function of business entities in order to make full use of resources to transport goods and to make better and perfect layout and execution of the whole logistics delivery process. Only on this basis can we make the logistics parks more competitive in fierce competition in the industry of logistics.

Model park entity layout and construction should be based on the following goals,

1) Avoiding waste of storage resources due to irrational structures,

2) Avoiding resource surplus due to unreasonable use of transport resources, such as a waste of space in planes, insufficient carrying by vehicles or rough outward transportation as there is some cargo.

3) Reasonable layout and organizing of transportation intermediaries is the effective and reasonable operation of the distribution center, such as long distance delivery, short distance air cargo transportation etc.

4) Sorting of scattered information resources should be made to avoid cargo transportation delay due to late information. For example, late updating of information resources would cause serious economic loss for customers.

2) Basic Principles of Aviation Logistics Park Layout

The work of effective aviation logistics parks is very complicated and it is also a complicated project. Logistics management should follow the following principles,

a) Principle of Economic Rationality

Money and time spent on the basis of effective attracting logistics business entities should be smallest and shortest so as to make reliable economic reserve for future logistics park expansion and functional extension.

b) Environmental Rationality Principle

To alleviate urban traffic pressure and to reduce the negative influence of logistics on environment is the main purpose of the logistics park layout and also the direct embodiment of the "people-orientation" layout idea.

c) Effective use of all resources to display full strength.

The development of modern logistics has a long and tortuous history. In a short time, all ideas cannot be taken into account. Therefore, in making systematic network layout in the logistics park system, we must pay attention to making full use and new integration of existing resources and construct and plan the logistics park to the best status with the best way in shortest time.

d) The principle of taking established key points as main pushed points, from shallow to deep and from fast to nearby.

The layout and construction of logistics parks has certain leading features and layout feature. But the blind operation or irrational operation can only cause bad consequences and make the whole enterprises fall into a state of confusion, resulting in a waste of resources, irrational structures and even paralysis. Therefore, we must adhere to the principle of taking the established key points as the main pushing points, from shallow to deep and from fast to nearby and rationally plan the construction of logistics park on the basis of considering practice and objective logistics development status and future trend analysis. At the same time, construction of the logistics park is a long-term task with a large scale and complex contents.

e) Unified Layout and Arrangement for Logistics Park System Layout Stage

At the stage of full-range and multi-level coordinating the logistics park system layout, we must pay attention to all the problems and make integration of various factors. As stressing on the infrastructure construction of logistics park system and logistics park system, we should take technical construction, management construction, policy construction and talent construction as key points to improve the logistics park's service quality and delivery efficiency.

\section{f) Principle to Coordinate with Overall Urban} Layout

The logistics park systematic layout falls into government behaviors and it is part of the urban layout. The logistics park layout should be based on the unified urban layout and overall arrangement, be adapted to the urban industrial structure adjustment and demand on space layout and be consistent with urban functional orientation and long-term development goals. 
g) Principle of Sustainable Development

Sustainable development refers to the sustainable development of society, economy and ecology. It is the principle for construction of economic and social construction. The layout and construction at the stage of logistics park systematic layout is adapted to the times and development of market economy to provide a good environment for economic development and operation. From the point of view of the overall effect on the society, we must create more social wealth and provide more convenience for people's life. In the aspect of environment protection, the logistics park should make layout based on the development mode of green logistics to reach the goal of green environment protection layout through recycling logistics and waste material logistics.

\section{B. Basic Methods of Aviation Logistics Park Facilities Layout}

\section{1) CORELAP layout method}

a) Design principle of CORELAP.

b) Determine order vector according to the accumulation of relationship between each facility and other facilities, the mutual relationship between them and operation areas.

The first is to position the facility firstly entering the layout as the largest TCR facility behavior. If the TCR value has more than one facility, we call it as a knot. Then, select the largest facility with the largest area to untie the knot. It the knot cannot be untied, make random choice. On a certain facility, we choose the facility at the last level to make knot un-ting, and so on. But if more than one knot happen in a same relationship, to choose the largest knot is ok.

c) Determination of Final Layout according to Facility Area.

When the layout vector is produced, put each facility into the graph well arranged according to the order. In arrangement, the form of the facility is mainly the square combination. The specific layout strategy should be to choose the largest TCR (NeighborClosenessRating) position.

d) Evaluation of Layout (Optimization of Layout)

Firstly, according to the logistics quantity processing, relationship between facilities is obtained to make analysis, the relationship between facilities will be divided into six levels: A, E, I, O, U, X, and we quantify the relationship between the value of the corresponding table, as follows:

\begin{tabular}{|c|r|r|r|r|r|r|}
\hline $\begin{array}{c}\text { Relation } \\
\text { Grade }\end{array}$ & $\mathrm{A}$ & $\mathrm{E}$ & $\mathrm{I}$ & $\mathrm{O}$ & $\mathrm{U}$ & $\mathrm{X}$ \\
\hline Relation & 4 & 3 & 2 & 1 & 0 & - \\
Value & & & & & & 1 \\
& & & & & & \\
\hline
\end{tabular}

Then, calculate the relationship values between selected facilities, work by the two values and the obtained value can display whether the plan is good. The larger the value is, the worse the scheme is.

\section{2) Systematic Layout Design Method SLP SLP Design Theory}

a) Make analysis of different facilities and their relationship to establish a facility relationship graph,

b) In determining different locations of different facilities, we can refer to the relationship graphs about whether different facilities are closely related and their distances are long. Establish the facility location correlation graph according to the position. Combine the correlation graph with the actual area of facilities to form the space graph.

c) Constant modification and perfection of diagrams related to facilities and areas for many different and reasonable layout programs,

d) The obtained layout scheme should be treated with the quantization scheme and the layout scheme should be evaluated through the weight coefficient method to get a quantitative index. With the index, different layout schemes should be marked. The scores obtained determine the quality of schemes. The less the score is, the worse the scheme is.

SLP design flow chart is shown in Figure 3.1.

3) Gradual Pushing Method

Another method of facilities layout is a heuristic method. This method can be divided into two parts. One is the new establishment method. It refers to starting from scratch and gradually increase work units until all the work layout is completed that we reach final plans such as PLA \&ET (plant Layout Analysis and Evaluation Technique). The other part is improvement method. This method starts from an already formed perfect scheme and calculate target functions through changing the facility positions to obtain better solutions that improvement cannot be further made. In this way, we will reach the final programs such as CRA \& FT (Computerized Relative Allocation of Facilities Technique). The improvement method is slower than the new establishment method, but it has a higher degree of optimization. The heuristic method of facilities layout is to get a plan similar to the best scheme. It is convenient and practical in operation. It is very suitable for solving large problems such as facility layout for aviation logistics parks.

\section{CONCLUSION}

Through description of the origin and development of the aviation logistics, we can see that the aviation logistics will occupy an important position in the logistics industry. It will be an important project in the future development. As carrier of aviation logistics, the importance of its status. Therefore, rational layout shall have more ration, informationization and internationalization. Through the examples on Shenzhen aviation logistics parks, we can see that the systematic layout on the aviation logistics park is based on theoretical basis. We believe that as the state pays more and more attention on aviation logistics, the aviation logistics development in China will tend to mature. The systematic layout of aviation logistics parks in China will become more and more rational and optimized.

\section{REFERENCES}

[1] Lu Hongwei, Layout in Aviation Logistics Park Layout [J], Logistics Engineering and Management, March 2010. 
[2] Yuan Kun, Importance of Development of Air Economy in China and Need to Command Key Points [J], June 2012.

[3] Wang Xiping, Study on Aviation Logistics Park Layout Design Based on Graph Theory and Gradually Pushing Method [J], Modern Trade and Business [J], June 2012.

[4] Zhao Min, Study on Jinan Yaoqiang Aviation Logistics Park Development Strategies [J], March 2012

[5] Cao Xueming, Wang Xifu, Study on Related Characteristics of Airport Logistics Park Layout [J], Traffic and Transportation, February 2013.

[6] Xu Xianfeng, Liang Wen, Discussion on Some Problems in Logistics Park Layout and Construction [J], Logistics Technology, October 2013.

[7] Mao Haijun, Li Xuhong, he Jie, Development Zone Professional Logistics Park Layout [J]. Journal of Traffic and Transportation Engineering, March 2012.

[8] Zhang Qian, Pan Jianping, A Method on Regional Logistics Park Layout Based on Weight Coefficient [J]. Journal of Beijing Jiaotong University (SOCIAL SCIENCE EDITION), February 2010.

[9] Chen Lihua, Liu Zhongyi, Study on New Development of Chinese Logistics Park [J]. Logistics Technology and Application, February .2013.
[10] Ma Ting. Study on Evaluation of Logistics Park Project Permission [J], Logistics Technology, January 2013.

[11] Pang Biao, Two Extremes in Logistics Estate [J], Chinese Logistics and Procurement, February 2013.

[12] Jiang Chaofeng, New Trend in Logistics Industry Environment Change and Warehousing Development.[J], Logistics Technology and Application, February 2013.

[13] Akber Syed F. Airport whole body X-ray scanners.[J]. Journal of Radiotherapy in Practice, 2012, Vol.11 (1), pp.5-6.

[14] Karpenko Nikita A. Incompressibility of quadratic Weil transfer of generalized Severi-Brauer varieties.[J]. Journal of the Institute of Mathematics of Jussieu, 2012, Vol.11 (1), pp.119-131.

[15] Ulrich Junker. Air traffic flow management with heuristic repair.[J]. The Knowledge Engineering Review, 2012, Vol.27 (3), pp.333342.

[16] Rhonda Lyons. Complexity analysis of the Next Gen Air Traffic Management System: trajectory based operations.[J]. Work, 2012, Vol.41 (Supplement), pp.4514-4522. 